\title{
FORMAÇÃO HUMANA PARA A CULTURA DE PAZ NO CONTEXTO SOCIAL CONTEMPORÂNEO
}

\author{
Maria Sheila Alves da Costa, Universidade Federa de Campina Grande (UFCG) \\ msheilinhares@gmail.com \\ Dorgival Gonçalves Fernandes, Universidade Federal de Campina Grande (UFCG) \\ dorgefernandes@yahoo.com.br
}

\begin{abstract}
RESUMO
O presente artigo objetiva refletir acerca das possibilidades de construção de uma educação que promova a formação humana em prol da cultura de paz na sociedade contemporânea. $\mathrm{O}$ estudo que enseja o artigo se constituiu como pesquisa bibliográfica, exploratória e analítica, tendo como referências teóricas Stuart Hall, Zygmunt Bauman, Manuel Castells e Paulo Freire. Os resultados do estudo apontam para a necessidade de construirmos uma educação que prime pelo respeito e acolhimento das diferenças identitárias individuais e coletivas, e chama a atenção para que a educação visando a cultura de paz pense na formação humana do sujeito que aprende e do sujeito que ensina.
\end{abstract}

PALAVRAS-CHAVE: Formação humana. Paz. Docência

\section{HUMAN FORMATION FOR CULTURE OF PEACE IN THE CONTEMPORARY SOCIAL CONTEXT}

\begin{abstract}
The article aims to reflect on the education while human formation for peace. Through the bibliographic, exploratory and analytical research, based on the theoretical references by Stuart Hall, Zygmunt Bauman, Manuel Castells and Paulo Freire, the study results show a need of an education with emphasis on the respect and acceptance of individual and collectives identity differences.
\end{abstract}

Key-words: Human Formation. Peace. Teacher Training 


\title{
FORMACIÓN HUMANA PARA LA CULTURA DE LA PAZ EN EL CONTEXTO SOCIAL CONTEMPORÁNEO
}

\begin{abstract}
RESUMEN
El artículo tiene como objetivo reflejar la educación como formación humana para la paz. Por medio de la investigación bibliográfica, exploratoria y analítica, teniendo como referencias teóricas Stuart Hall, Zygmunt Bauman, Manuel Castells y Paulo Freire, los resultados muestran la necesidad de una educación que prima por el respeto y la acogida de las diferencias.
\end{abstract}

PALABRAS CLAVES: Formación humana. La Paz. Formación docente.

\section{INTRODUÇÃO}

Estamos inseridos em um tipo de sociedade, a sociedade ocidental moderna, e ainda que para um grupo de pensadores estejamos vivenciando-a na sua versão pós-moderna, ainda estamos severamente implicados com os valores, ritos e princípios da modernidade. Mas, é evidente, vivemos em um período histórico marcado por transformações significativas nos diversos âmbitos da vida: econômico, político, cultural, religioso e educacional. Em meio a tantas transformações, a sociedade atual tem sido marcada por uma forte cultura de violência que se contrapõe aos valores humanos, princípios de civilidade e cultura de paz, pensados e promulgados na modernidade, mais especificamente a partir do fim da década de 1940, no pós Segunda Guerra Mundial.

Neste contexto marcado pela cultura da violência, pensando o homem como sujeito social e político, nos propomos no escopo deste artigo a pensar nas condições de possibilidade para se erigir uma formação humana tendo em vista a cultura de paz. Para concretizar esse objetivo, o presente texto tem como base uma pesquisa de natureza bibliográfica, exploratória e analítica assentada teoricamente no pensamento de autores, tais como Stuart Hall, Zygmunt Bauman, Manuel Castells e Paulo Freire, entre outros. No desenho acadêmico pensado para este artigo, nos centramos na questão da identidade, considerando, de modo mais específico, os processos sociais que tem almejado a inferiorização de múltiplas identidades culturais que 
se diferenciam do padrão identitário tradicional cujo pressuposto de poder se pauta na branquidade, heterossexualidade, cristandade, masculinidade e elitismo econômico.

\section{A CONSTITUIÇÃO DO SUJEITO SOCIAL}

Ao nascer, somos inseridos em um tipo de sociedade que nos antecede e na qual iniciamos, a priori inconscientemente, desde a tenra infância, o processo de construção de nossas crenças, valores, conceitos e costumes, e passamos assim, a agregar significância à nossa existência individual e convivência social a partir de determinada concepção de sujeito que, conscientemente ou inconscientemente, nos é imposta pelos padrões culturais. Tal concepção nos aponta um modo de ser, pensar e agir em relação a nós mesmos e aos outros sujeitos.

Para Hall, existem três concepções de sujeito que se conjecturam de acordo com o período sócio-histórico vivenciado por cada um. O autor os classifica como: sujeito Iluminista, sujeito Sociológico e sujeito Pós-moderno (2006, p. 10). O sujeito iluminista externava sua reflexão sobre o mundo por meio do conhecimento positivista pautado essencialmente no antropocentrismo, não mais no teocentrismo. As suas relações eram sóbrias, racionais e desejavelmente homogêneas, os laços familiares e afetivos eram intensos e duradouros, preservando uma cultura patriarcal.

Posteriormente surge o sujeito sociológico. Este apresentava fortes e calorosas interações sociais que buscavam compreender o outro e valorizar sua autonomia, tendo em vista que, mesmo sendo autônomos, os sujeitos necessitam um do outros para manterem a sociedade em bom funcionamento. Por fim, bem mais diferenciado e próximo à realidade atual, Hall nos remete à identificação do sujeito pós-moderno, caracterizando-o pelas relações inconstantes, incertas, variáveis, fragmentadas, heterogêneas e existenciais que se intensificam por meio da acelerada globalização cultural. Nas palavras do sociólogo:

O sujeito pós-moderno, conceptualizado como não tendo uma identidade fixa, essencial ou permanente. A identidade torna-se uma "celebração móvel": formada e transformada continuamente em relação às formas pelas quais somos representados ou interpelados nos sistemas culturais que nos rodeiam (HALL, 2006, p.12-13). 
Diante dessa perspectiva do autor, devido a tais transformações que podem desestruturar atualmente o que já se tem como certo, inicia se aí o estopim para a crise existencial que afeta boa parte dos sujeitos da sociedade dita pós-moderna, pois segundo Hall (2006, p.7):

As velhas identidades, que por tanto tempo estabilizaram o mundo social, estão em declínio, fazendo surgir novas identidades e fragmentando o indivíduo moderno. A assim chamada "crise de identidade" é vista como parte de um processo mais amplo de mudança, que está deslocando as estruturas e processos centrais das sociedades modernas e abalando os quadros de referência que davam aos indivíduos uma ancoragem estável no mundo social.

Logo, quando pensamos acerca da construção cultural do sujeito pela perspectiva do resultado da desestabilização do padrão social tradicional e consideramos a situação de violência que aflige a sociedade contemporânea marcada por atos terroristas nos países ocidentais desenvolvidos, e no caso brasileiro, com a onda de assaltos, roubos, assassinatos, estupros e desrespeito aos direitos sociais, nos deparamos com o efeito do julgamento opressor de uns sujeitos sobre outros sujeitos que se colocam na condição da diferença.

Cremos ser possível analisar essas situações de violência inspirados no pensamento de Hall, a partir da ideia de desconstrução das referências identitárias, no caso, as referências já construídas em relação ao sujeito pacífico que prima pela paz como condição indispensável para o bem viver coletivo. Ou seja, esse processo de desconstrução é também um processo de construção de referências móveis, porém, ainda que sejam referências móveis, muitos sujeitos ao construírem as suas referências do que para ele seja o correto, as compreendem como uma espécie de estabilidade e raciocínio tido como pronto e anulável, e o que não coincidir passa a ser, de alguma forma, refutado. Desse modo, as referências identitárias móveis, mesmo que sejam provisórias, podem servir a uma condição social de liberdade ou de opressão do outro.

Podemos compreender essa situação recorrendo ao pensamento de Bauman (2005, p.13). Este diz: "Qualquer que seja o campo de investigação em que se possa testar a ambivalência da identidade, é sempre fundamental distinguir os pólos gêmeos que esta impõe à existência social: a opressão e a libertação". Neste caso, para o outro, o diferente, pode ser remetida a opressão, assentada na indiferença ou no estranhamento, o que torna possível a intolerância. 


\section{O ESPELHO DE SI}

Quem eu gostaria que o outro fosse? Como formá-lo a meu molde? Quais deveriam ser os valores sociais predominantes? Quais são as contribuições da educação para isso? Parece-nos óbvio que poderíamos encontrar diferentes respostas para as mesmas perguntas, entretanto, possivelmente sem nos darmos conta, muitas vezes desejamos que o outro seja o espelho de nossas aspirações mais íntimas. O que, dessa maneira, consciente ou inconscientemente, produz subjetivamente a anulação do outro que não é igual a mim, para produzir uma espécie de satisfação. Nesta perspectiva, como assinala Bauman (2005, p. 27):

[...] cada sociedade produz sua própria espécie de estranhos, e os produz a sua própria maneira, imitável. Se os estranhos são as pessoas que não se encaixam nos mapas cognitivos, moral ou estético do mundo - num desses mapas, em dois ou três; se eles, portanto, por sua simples presença, deixam turvo o que deve ser transparente, confuso o que deve ser uma coerente receita para ação, e impedem a satisfação [...] sendo assim acusados de causar a experiência do malestar como a mais dolorosa e menos tolerável.

À mostra do que fala Bauman, podemos pensar: se para a moral política de países ocidentais o conceito de paz significa estabelecer alianças pacíficas com os demais países propondo "respeitar" as suas diversidades, buscando como finalidade maior a ausência de guerras que manterão a ordem do status pacífico democrático, para países orientais, o estado pacífico, na maioria das vezes, é obtido por meio da promoção de conflitos, compreendidos como necessário para a paz. Tal consideração nos remete à reflexão sobre a organização social contemporânea empreendida por Castells. Diz esse pensador (2008, p.17):

Essa nova forma de organização social, dentro de sua globalidade que penetra todos os níveis da sociedade, está sendo difundida em todo o mundo, do mesmo modo que o capitalismo industrial disseminado no século XX, abalando instituições, transformando culturas, criando riquezas e induzindo a pobreza, incitando a ganância, a inovação e a esperança, e ao mesmo tempo impondo o rigor e instilando o desespero. Admirável ou não, trata-se na verdade de um novo mundo. 
Tendo em vista tantas dicotomias, como a educação poderia atuar na organização social globalizada em prol da cultura de paz para o progresso de uma sociedade tão pobre em valores humanos? Essa indagação nos leva a outras: Que mundo é esse em que vivemos na atualidade? Um mundo em que o outro deve viver e ser tratado em condições de vulneráveis que nem eu mesmo acolheria para mim? No mesmo sentido no qual encaminhamos tais indagações, isto é, no sentido da perplexidade e indignação, afirmamos a tristeza pela constatação na nossa realidade social a existência de tantas pessoas, próximas ou distantes, vivendo em condições subumanas, sem oportunidades de ter educação formal de qualidade, e mesmo vivendo em condições apenas suficiente para manter-se biologicamente vivas.

Mas, será que viver humanamente é viver apenas para manter-se fisicamente vivo? Com certeza, não! É direito assegurado pela Constituição brasileira, (BRASIL, 1998) que, cada cidadão tenha direito à saúde, trabalho, moradia, lazer e educação, sendo essa, primordialmente, de qualidade. Entretanto, sabemos que tais direitos são efetivamente gozados apenas pelas classes sociais economicamente favorecidas, considerando-se a elevada desigualdade social brasileira, essa desigualdade social se reflete na construção e interação do sujeito enquanto indivíduo e coletivo. E se pensamos na condição atual do sujeito enquanto cidadão seja ocidental ou oriental, muitas são as necessidades humanas socialmente demandadas e não cumpridas. Neste caso, a sociedade fraterna e igualitária por muito sonhada e desejada tem se constituído como um horizonte distante. Como afirma Giddens (2005, p.279): "Na prática, porém, a igualdade revela-se difícil de ser atingida. Em um sistema de livre-mercado, as desigualdades são inevitáveis".

Mas, o sonho de uma sociedade altruísta, sonhado por tanto homens e tantas mulheres ao longo da história humana precisa continuar a ser sonhada, fazendo-se necessária a luta que objetiva a materialidade do sonho. Assim, enxergar criticamente a realidade não é o bastante, é necessário o agir com ela e sobre ela. Neste caso, Freire (1987 p. 37) nos adverte: "A realidade social, objetiva, que não existe por acaso, mas como produto da ação dos homens, também não se transforma por acaso. Se os homens são produtores desta realidade [...], transformar a realidade opressora é tarefa histórica, é tarefa dos homens".

Sendo assim, seguindo as pegadas de Freire e entendendo o papel atribuído por ele à educação nessa tarefa transformadora do contexto cultural insatisfatório, injusto e opressor que cerceia direitos sociais, é necessário que nos centremos na tarefa de pensar e organizar as 
práticas educacionais no sentido de construirmos o processo transformador, entendendo a educação como condição de possibilidade prioritária para que possa ser criada pelos homens a sociedade fraterna, justa e humanizante, que eleva o sujeito à condição de "ser mais" (FREIRE, 1987).

Neste sentido é que advogamos a favor de uma educação sistematizada, formal que tenha como conteúdo de ensino a produção, apreensão e desenvolvimento de valores humanos que encaminhem os sentidos e feições de uma cultura de paz. Desse modo, sobre a educação e a cultura de paz, concordamos plenamente Viegas et al (2016, p. 79) quando faz a seguinte afirmação:

É unanimidade reconhecer que educar é tarefa importante basilar na construção de sociedades alinhadas com a paz, a justiça social e o estado de bem-estar coletivo. Mas fazer afirmação tão óbvia requer certa dose de cuidado e especificação, tendo em vista que os discursos, de tão banalizados, invisibilizam questões fundamentais: Como educar? Qual aspecto do conhecimento a se explorar? Educar servindo a quem? $\mathrm{Na}$ arena social, qual a agenda definida para o conhecimento? E a escola, como posiciona-se diante da sociedade?.

Considerando-se as indagações postas por Viegas em contraposição ao nosso modelo educacional vigente, que muitas vezes pensa e propaga a educação como comercio , retirando-a da condição de bem comum para colocá-la na condição de mercadoria a ser ofertada e vendida no grande mercado educacional em função de determinado modelo de progresso, é mister salientar, como o fazem Feitosa e Fernandes (2011), a necessidade e a importância de construirmos práticas educativas que articulem cognição e emoção e que valorizem a cultura de paz, do sustentável e da solidariedade entre os sujeitos sociais a partir das suas diversas diferenças étnicas, sexuais, culturais e de gênero. Eis a possibilidade de pensarmos e praticarmos a formação humana centrada em valores que favoreçam a realização individual e coletiva dos sujeitos sociais com as suas diferenças identitárias. Mas não devemos pensar apenas na formação dos sujeitos que aprendem, mas também na formação dos sujeitos que ensinam, ou seja, faz-se necessário, com urgência, pensarmos coletivamente a questão da formação docente para a cultura de paz. 


\section{CONCLUSÃO}

Neste artigo, procuramos refletir sobre as condições de possibilidade de construirmos uma concepção de educação e de práticas educativas que, trabalhando com as noções de cultura de paz, do sustentável e da solidariedade como conteúdo de ensino que prime pela construção de valores humanos, em contraposição à ideia de educação como mercadoria a ser consumida no mercado educacional em benefício de determinado modelo de progresso. Ademais, advogamos que a educação, por nós entendida como um bem comum seja, produtora de atitudes de respeito e de acolhimento às diferenças identitárias individuais e coletivas como caminho para a construção de uma sociedade igualitária, fraterna e justa. Para tanto, faz-se necessário pensarmos a formação humana dos sujeitos que aprendem e dos sujeitos que ensinam.

\section{REFERÊNCIAS BIBLIOGRÁFICAS}

BAUMAN, Z. Identidades. Tradução de Carlos Alberto Medeiros. Rio de Janeiro: Zahar, 2005.

CASTELLIS, M. O poder da identidade. Tradução de Klassus Brandini Gerhardt. edição. São Paulo: Paz e Terra, 2008.

FEITOSA, A. F. M. A; FERNANDES, D. G. Educação, Progresso e Autorrealização Humana: a ética da sustentabilidade. In: MATOS, Kelma S. Lopes de (Orga). Cultura de Paz, ética e espiritualidade II. Fortaleza: Edições UFC, 2011, p. 249-263.

FREIRE, P. Pedagogia do oprimido. 17. Ed. Rio de Janeiro, Paz e terra, 1987.

GIDDENS, A. Sociologia. Tradução de Sandra Regina Netz. 4. Ed. Porto Alegre: Artmed, 2005.

HALL, Stuart. Identidades Culturais na pós-modernidade. Tradução de Tomaz T. da Silva e Guaciara L. Louro. 11. Ed. Rio de Janeiro: DP\&A, 2006.

BRASIL. Constituição da República Federativa do Brasil. Brasília, DF: Senado Federal: Centro Gráfico, 1988.

VIEGAS, A. P. S. M. P et al. A ESCOLA RESSIGNIFICANDO AS RELAÇÕES: A educação inclusiva valorizando as diferenças e promovendo a cultura de paz. In: MATOS, 
Kelma S. Lopes de $\left(\mathrm{Org}^{\mathrm{a}}\right)$. Cultura de Paz, educação e espiritualidade III. Fortaleza: EdUECE, 2016, p. 71-84. 